\title{
hIgDFc-Ig inhibit B cell functions by regulating BCR-Lyn-Syk-NF-xB signaling pathway in treatment for mice with collagen-induced arthritis
}

Xianzheng Zhang ${ }^{1}$, Li Xu ${ }^{1}$, Dan Mei ${ }^{1}$, Jinru Ge ${ }^{1}$, Han Wang ${ }^{1}$, Yu Tai ${ }^{1}$, le han ${ }^{1}$, Jinling Shu ${ }^{1}$, Faqin Liang ${ }^{1}$, Xiaoyu Cai ${ }^{1}$, Yue Zhu ${ }^{1}$, Qianqian $\mathrm{Yu}^{1}$, feng zhang ${ }^{1}$, Qing-Tong Wang ${ }^{1}$, Ling-Ling Zhang ${ }^{1}$, and Wei Wei ${ }^{1}$

${ }^{1}$ Anhui Medical University

May 6, 2020

\begin{abstract}
Abstract Background and purpose: To investigate the effect of hIgDFc-Ig (DG), a new biological agent targets competition for binding to IgD receptors, on collagen-induced arthritis and its potential mechanism in regulating B cell antigen-receptor signaling pathway. Experimental approach: DBA1 mice were used to establish collagen-induced arthritis model, three doses DG were administered by intraperitoneal injection. Clinical assessment of CIA, histopathological examination, flow cytometry, western blotting, immunofluorescence staining, protein chips and so on were used to evaluated therapeutic effects. The competitive effects on BCR-NF- $x$ B signaling pathway were also evaluated in Daudi cell lines in vitro. Key results: We found that DG has a obvious therapeutic effect on CIA mice. DG relieved the clinical assessment of CIA mice and improved the pathology of joints and spleen. In addition, regulated B cell subsets in the PBMC and spleen of CIA mice, and decreased level of immunoglobulins. DG can inhibit the over-activation of BCR signal by increasing p-Lyn level, Co-treatment with DG (0.1-10 $\mu \mathrm{g} \cdot \mathrm{ml}-1)$ dosedependently down-regulated the BCR signaling and decreased the iteraction between Syk and Btk stimulated by IgD in Daudi cell. Conclusion and Implications: DG may play a therapeutic role in CIA mice by regulating BCR-Lyn-Syk-NF-KB signaling pathway, and may be a new promising biological agent for rheumatoid arthritis. Key words: hIgDFc-Ig; B cell antigen receptor; Collagen-induced arthritis; NF- $\varkappa \mathrm{B}$ signaling pathway
\end{abstract}

\section{Hosted file}

manuscript (1).doc available at https://authorea.com/users/318378/articles/448301-higdfcig-inhibit-b-cell-functions-by-regulating-bcr-lyn-syk-nf-\%CE\%BAb-signaling-pathway-intreatment-for-mice-with-collagen-induced-arthritis 
Figure 1

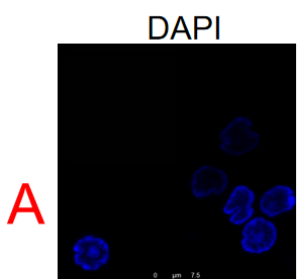

DAPI
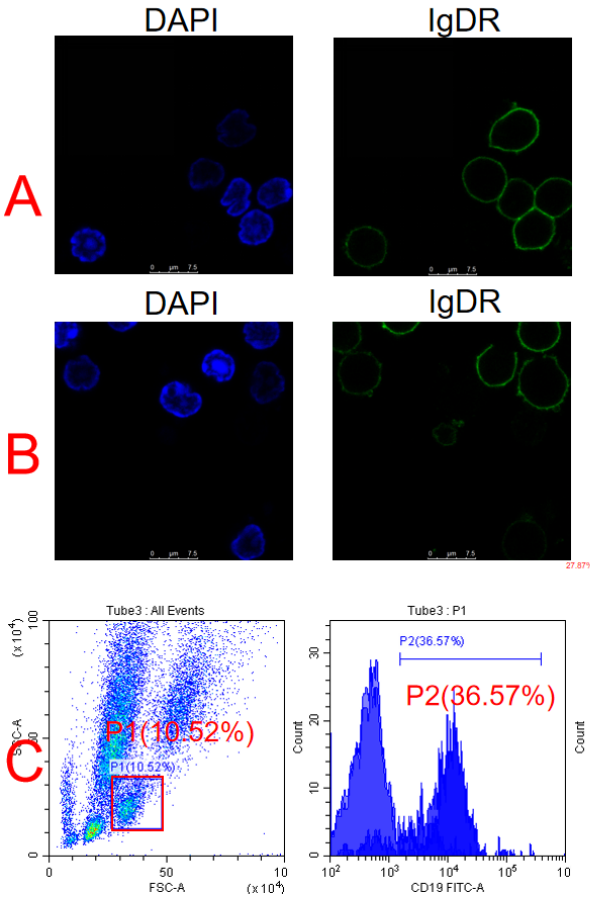

$\lg \mathrm{DR}$
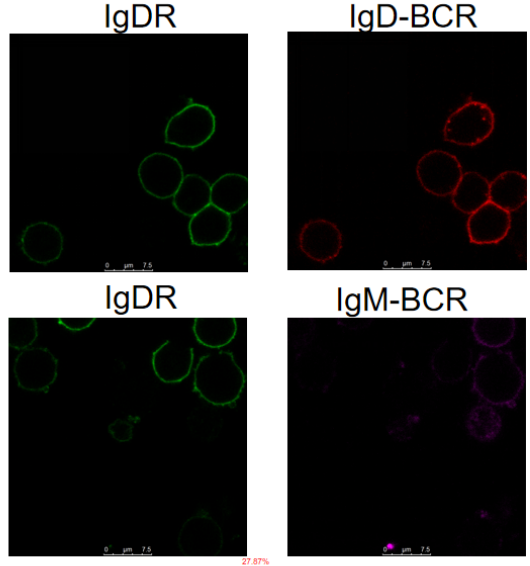

IgM-BCR
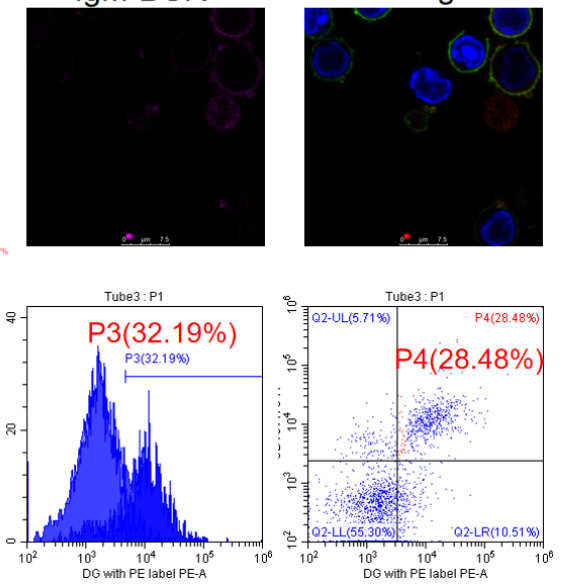

Figure 2

A

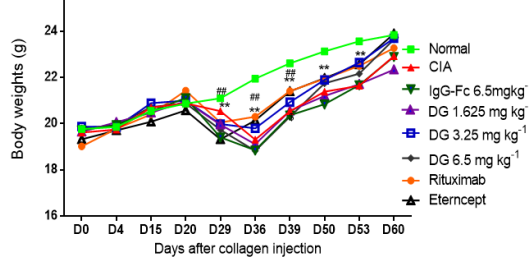

B
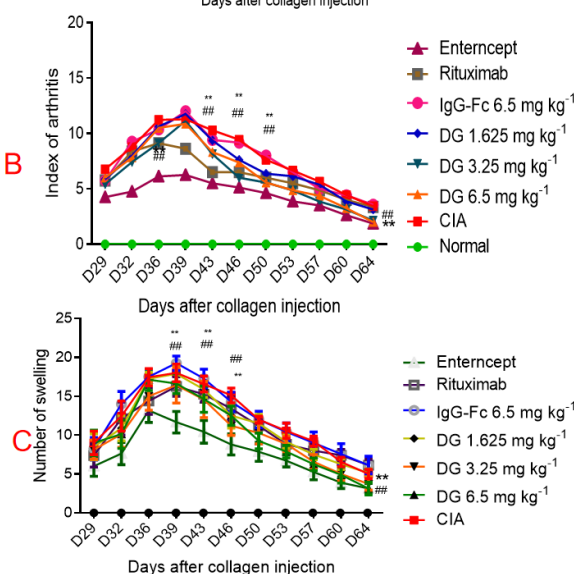

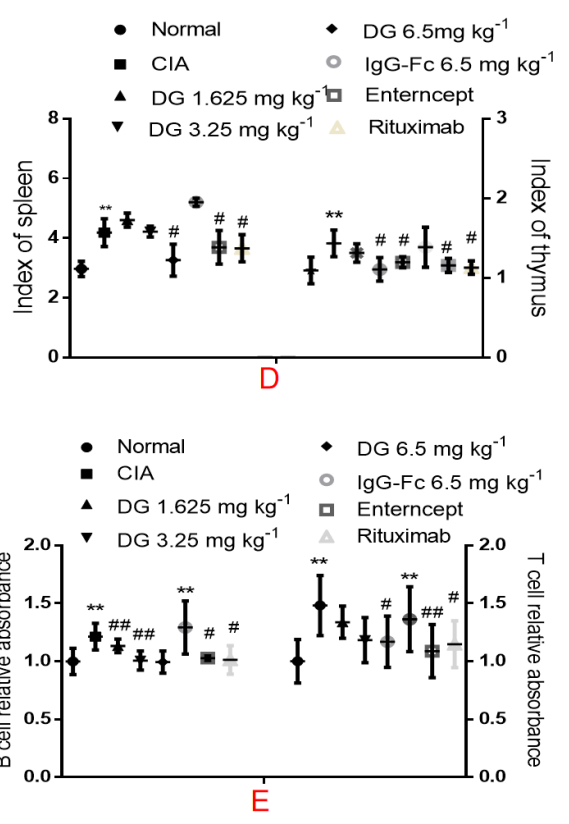



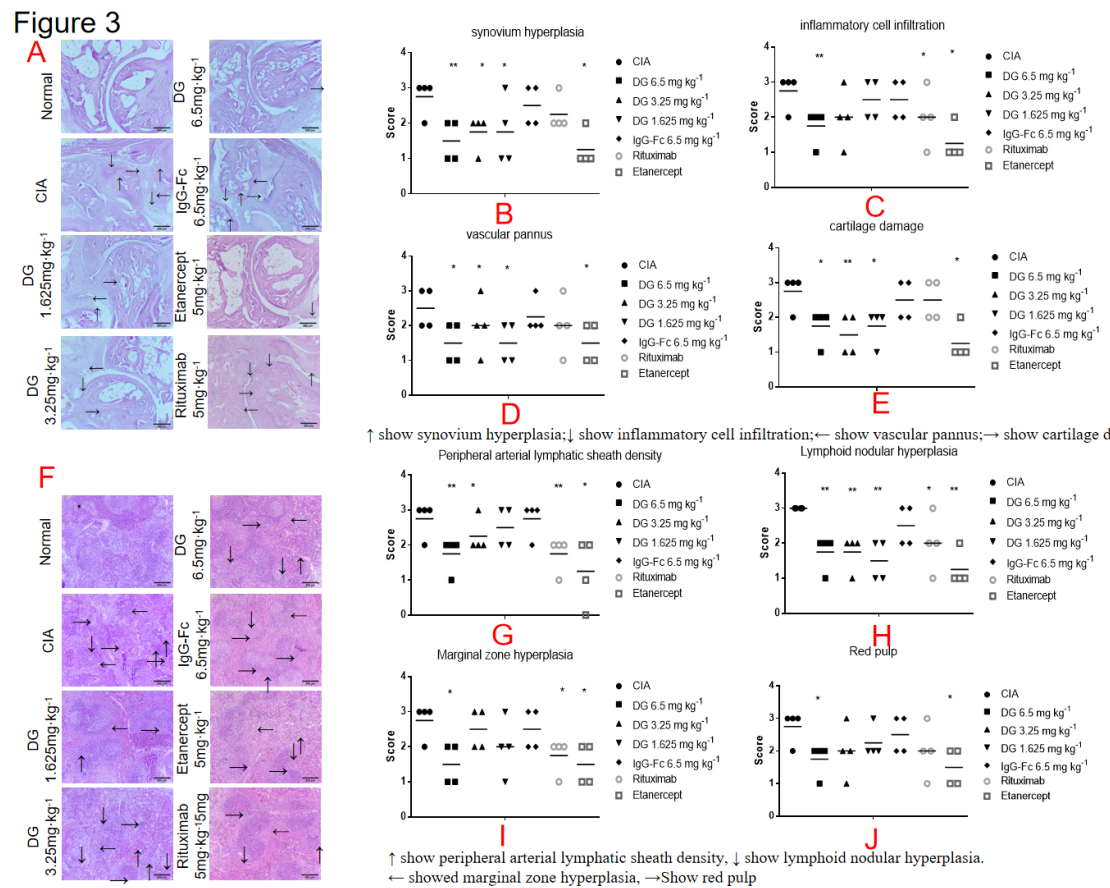

$\uparrow$ show synovium hyperplasia; $\downarrow$ show inflammatory cell infiltration; $\leftarrow$ show vascular pannus; $\rightarrow$ show cartilage damage
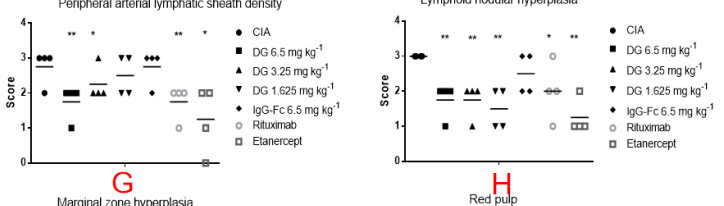

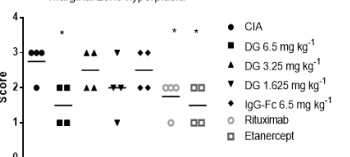

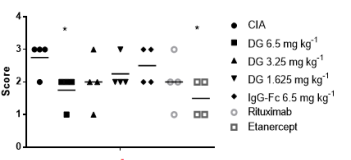

$\uparrow$ show peripheral arterial lymphatic sheath density, $\downarrow$ show lymphoid nodular hyperplasia. $\leftarrow$ showed marginal zone hyperplasia, $\rightarrow$ Show red pulp
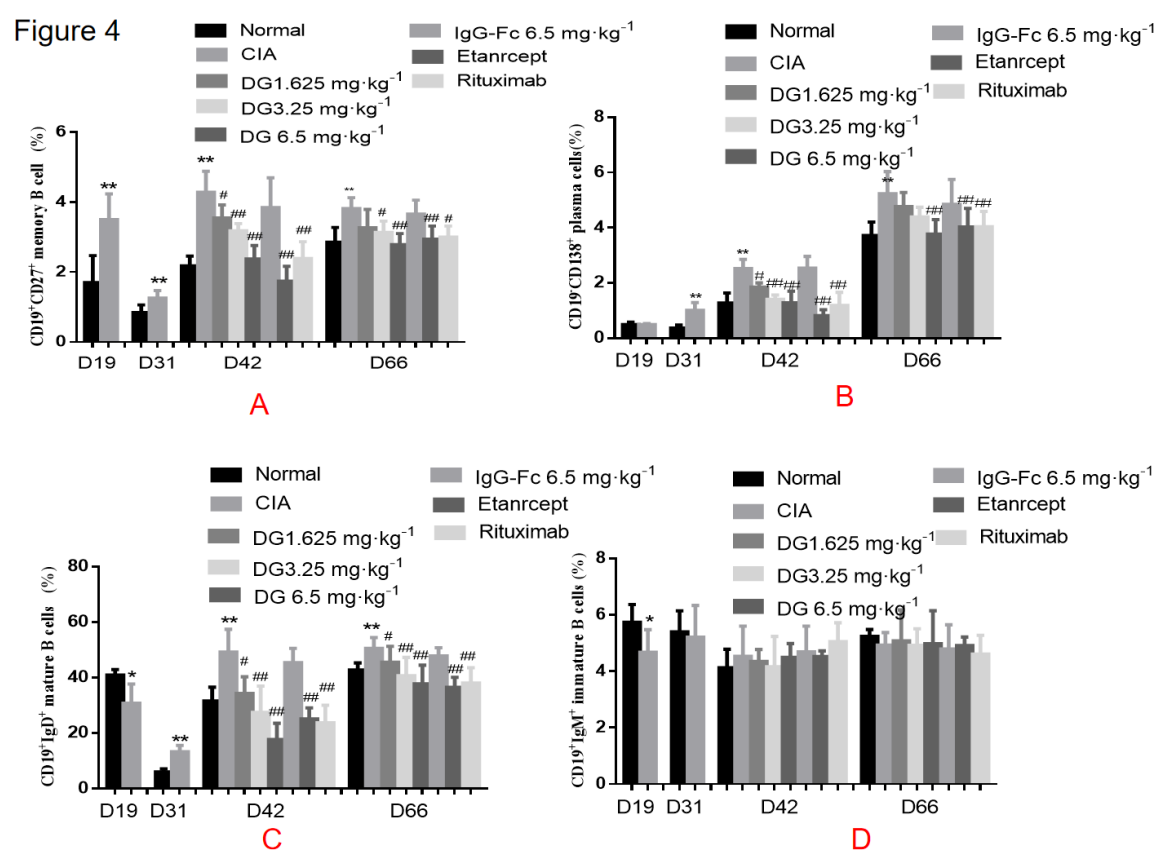

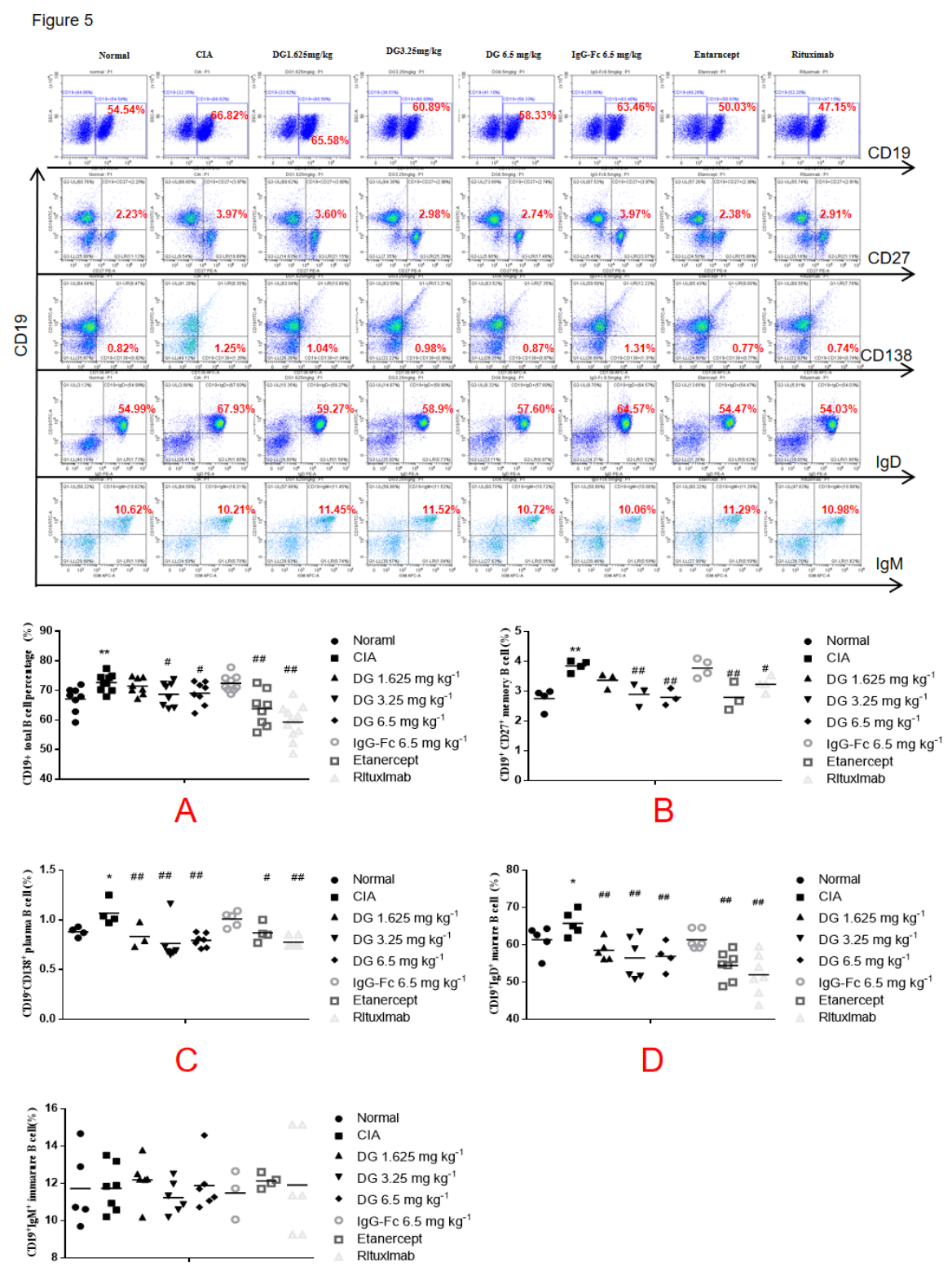

E 


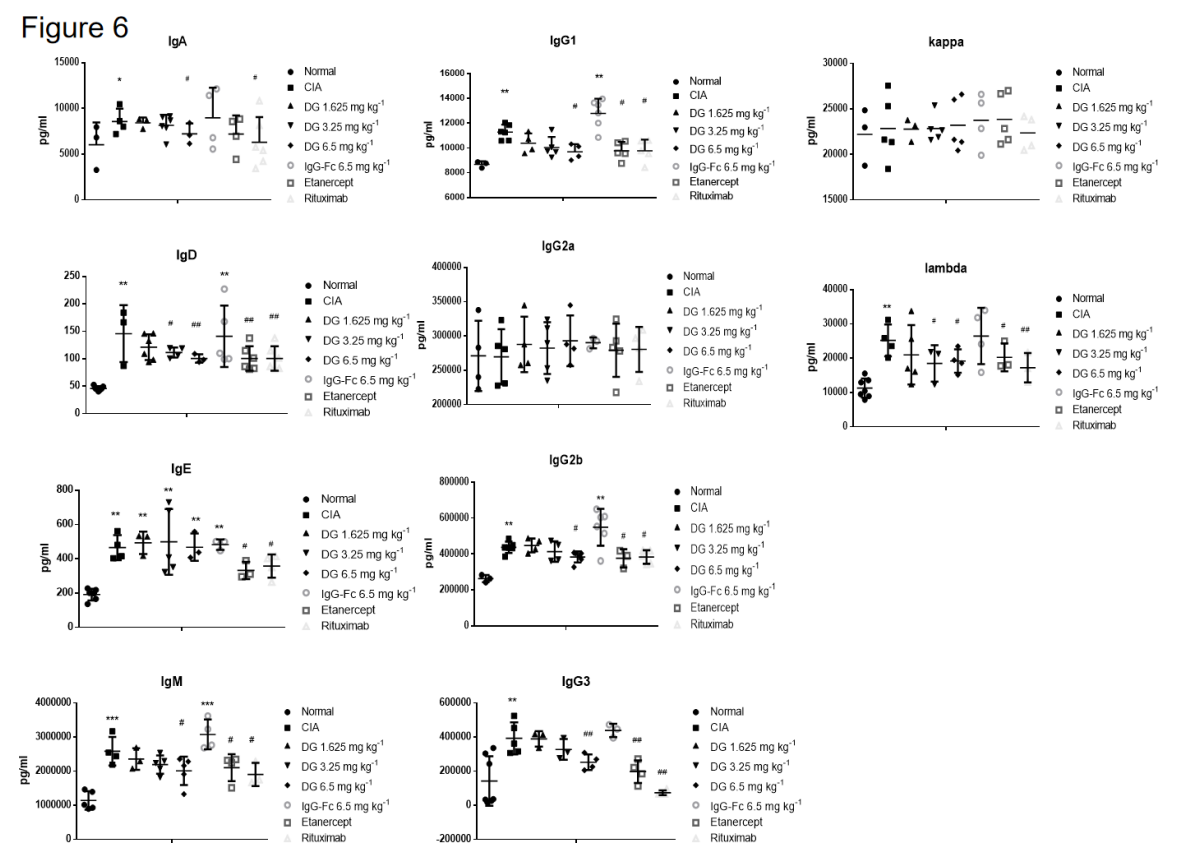


Figure 7
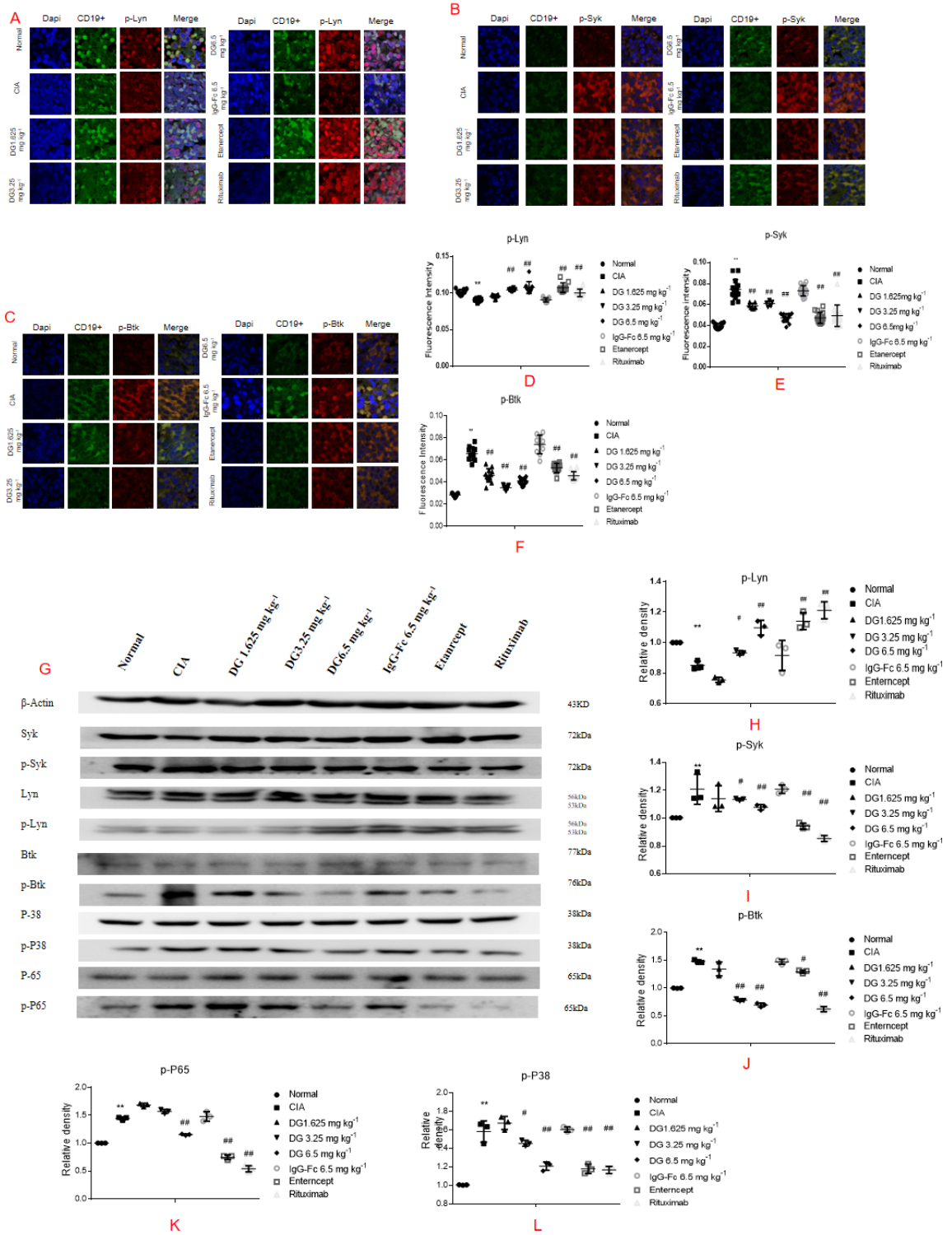
Figure 8
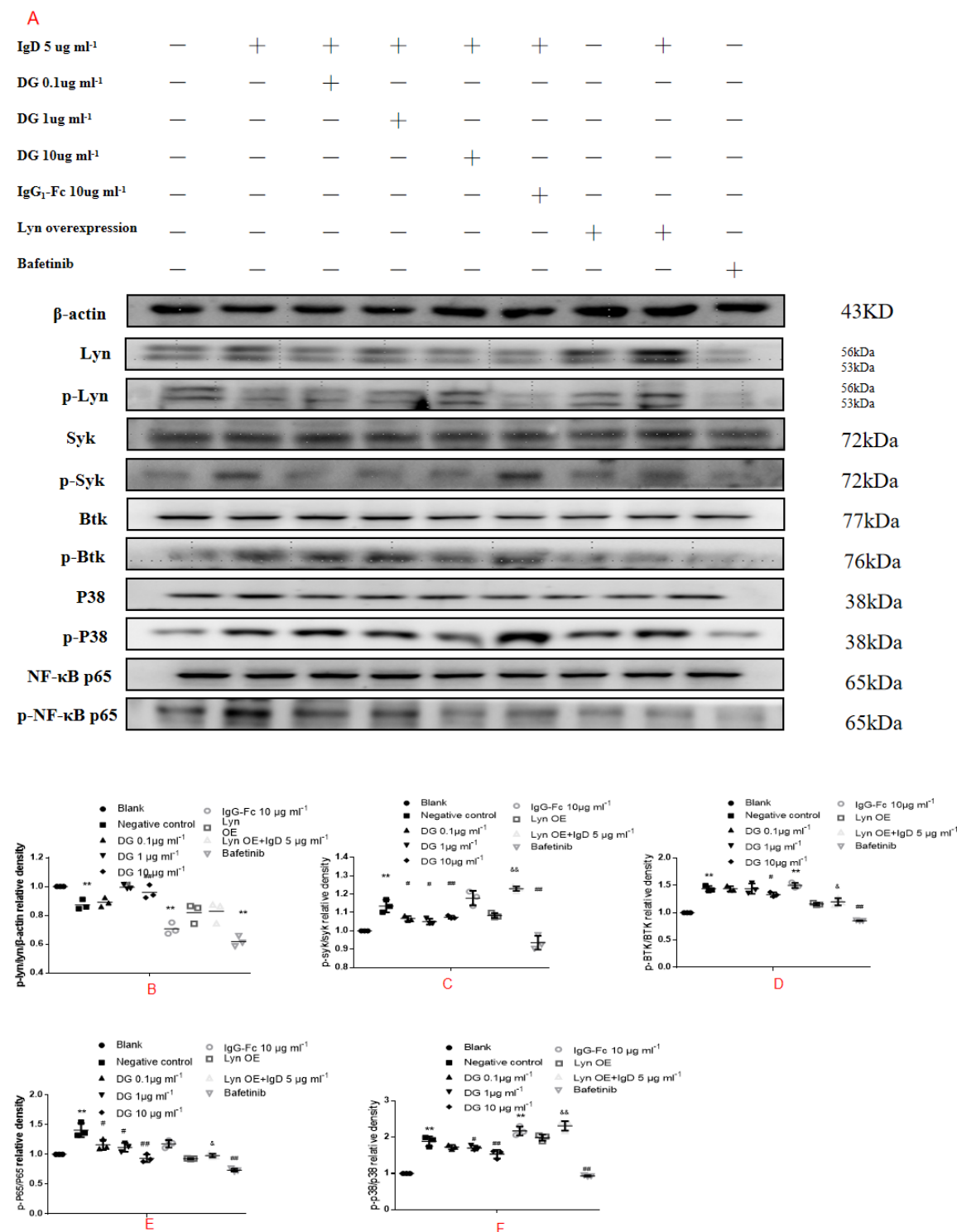
Figure 9
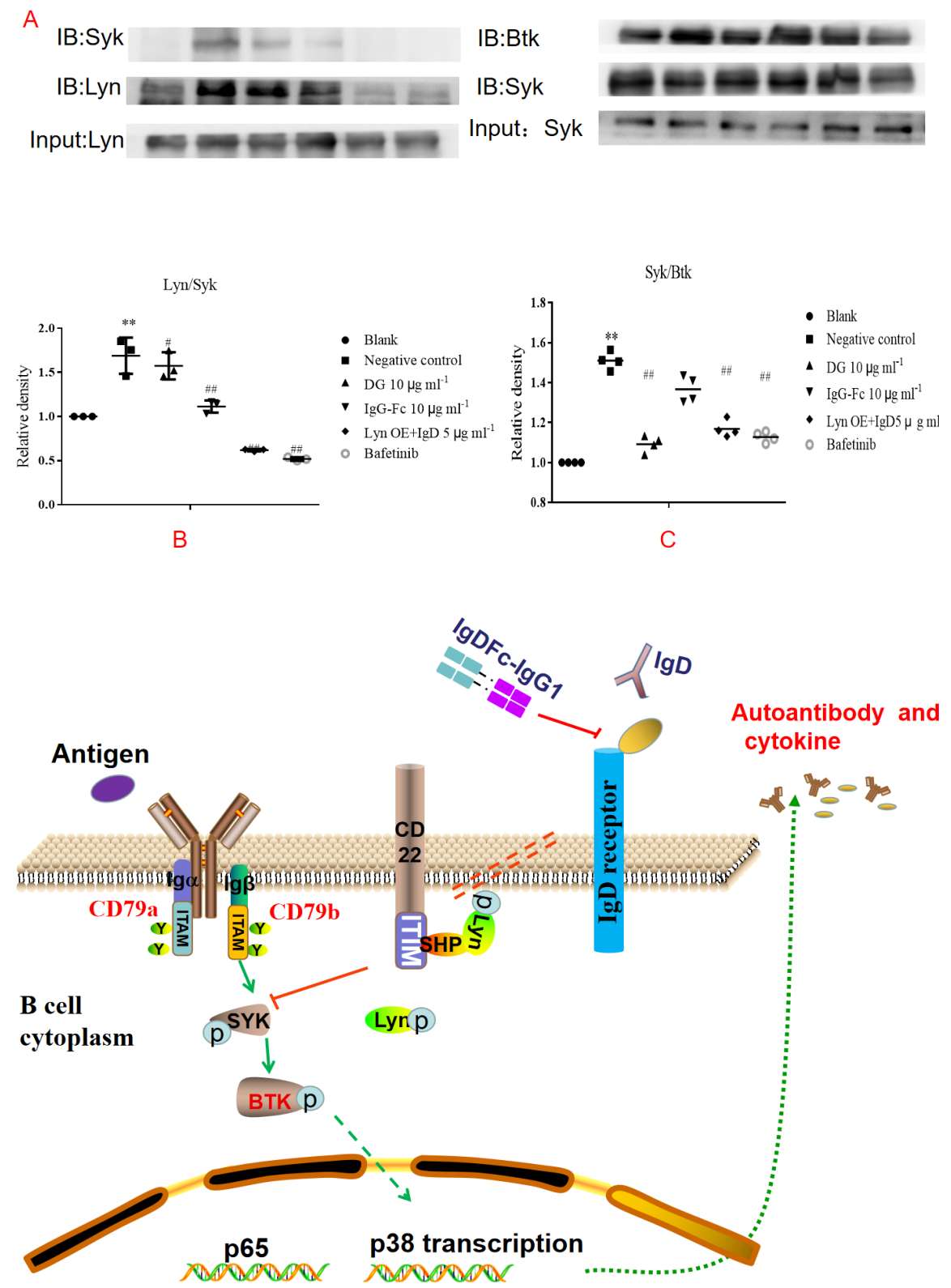